\title{
Radiographic changes in early rheumatoid disease
}

\author{
ANDREW BROOK* AND MARY CORBETT \\ From the Department of Rheumatology, Middlesex Hospital, London
}

SUMMARY We have studied the radiological features in 94 patients with early rheumatoid disease followed prospectively for 5 years. The changes appeared very early and occurred in up to $71.3 \%$ of patients. Erosive changes occurred in the feet much more commonly than in the hands and considerably earlier. Erosive changes were present before there was joint-space loss. Frequent $x$-ray examination of feet and hands in the first 2 years after presentation is required if we are to identify patients at risk for serious joint damage.

\begin{abstract}
A recent prospective study of early rheumatoid disease has enabled us to follow the radiological features almost from onset. Although the radiographic appearances were described by Nichols and Richardson in 1909, correlation with modern clinical classification was not made until 1932 (Scott). The frequency of the various $x$-ray manifestations was reported by Fletcher and Rowley in 1952. Subsequently, large surveys (Soila, 1958; Berens and Lin, 1969) have shown that $x$-ray abnormalities may be an early feature. Soila studied the films of 1032 patients but compared only the first $x$-rays with the last, the interval between the two sets of films being anything up to 6 years. Furthermore, $x$-rays of the feet were not taken as often as $x$-rays of the hands. We have therefore reviewed our material in order to establish a more complete study of radiological manifestations with respect to time.
\end{abstract}

\section{Patients and methods}

The design of the Middlesex Hospital Prospective Study of early rheumatoid disease has been described (Fleming et al., 1976a, b) and the present material is taken from the 102 patients seen within one year of onset and followed up for at least 21 months or until death. The mean radiological follow-up of all patients was $63 \cdot 1$ months.

Each patient was $x$-rayed on presentation and then annually. Radiographic follow-up was inade-

Accepted for publication May 2, 1976

*Present address: Woden Valley Hospital, Canberra, A.C.T. 2606, Australia

Correspondence to Dr. M. Corbett, Department of Rheumatology, Middlesex Hospital, Arthur Stanley House, Tottenham Street, London W1P 9PG quate in 8, leaving 94 patients on whose films this study is based (41 men, 53 women). $X$-rays of hands (posteroanterior) and feet (anteroposterior) were done as part of the routine outpatient service. The films were read by the same observer (A.B.) consecutively and without knowledge of the clinical state. Osteoporosis, erosions, joint-space narrowing, and periosteal reaction were looked for. We accept that interobserver and intraobserver errors in such readings are considerable (Kellgren, 1956) and this paper is concerned only with changes confirmed in subsequent $x$-rays by the same observer.

Erosive changes were regarded as 'diagnostic' if there were two large erosions $(1.5 \mathrm{~mm}$ or more of cortical defect). Smaller erosions and subchondral cysts were included in assessment of the extent and progression of involvement. The 'pre-erosive' changes described by Fletcher and Rowley (1952) in the cortex were not found to be a sufficiently reliable guide to the subsequent development of erosions at that site. Osteoporosis was subjectively graded as absent, definite, or severe. Joint-space loss was recorded only if unequivocal. Periosteal reactions were too few to add to the diagnostic value of the films.

\section{Results}

EROSIVE ARTHROPATHY

Of 94 patients, $67(71.3 \%)$ developed 'diagnostic' erosions, $5(5.3 \%)$ 'nondiagnostic' erosions, and 22 $(23.4 \%)$ showed no change. Mean follow-up of the 22 patients was 64 months.

TIME FROM ONSET OF JOINT SYMPTOMS TO DIAGNOSTIC X-RAY CHANGE (TABLE 1)

Of those developing erosions, $29(43.3 \%)$ did so in the first year. $31(46.3 \%)$ became erosive in the 
Table 1 Number of patients developing 'diagnostic' erosive change. Time from first joint symptom

\begin{tabular}{lllll}
\hline Time $(m)$ & $\begin{array}{l}X \text {-ray } \\
\text { of hands }\end{array}$ & $\begin{array}{l}X \text {-ray } \\
\text { of feet }\end{array}$ & $\begin{array}{l}\text { Hands and } \\
\text { feet }\end{array}$ & Total \\
\hline $0-12$ & 5 & 12 & 12 & 29 \\
$13-24$ & 6 & 8 & 17 & 31 \\
$25-36$ & & 2 & 3 & 5 \\
36 & 2 & 32 & 2 \\
Total & 11 & 24 & 67 \\
\hline
\end{tabular}

second year, $5(10.5 \%)$ in the third year, 1 in the fourth year, and 1 in the fifth.

\section{SITE OF FIRST APPEARANCE OF EROSIONS}

(TABLE 2)

Of the 67 who developed diagnostic erosions, the erosions appeared first of all in the feet in 24 $(35.8 \%)$, first in the hands in $11(16.4 \%)$, and in both simultaneously in $32(47.8 \%)$. Table 2 includes the frequency with which these sites were affected alone or in association with another site. By far the most common were the metatarsophalangeal (MTP) joints which were first affected in $52(77.6 \%)$ patients, $26(38.8 \%)$ of whom had erosions only in the MTP joints. The next most common site were the bones in or around the wrist joint where $23(34.3 \%)$ patients showed erosions, $14(20.9 \%)$ of them in the ulnar styloid process.

Table: 2 Site of first diagnostic erosions (67 patients)

\begin{tabular}{lccc}
\hline Site & $\begin{array}{l}\text { Involved } \\
\text { alone }\end{array}$ & $\begin{array}{l}\text { Involved with } \\
\text { another site }\end{array}$ & Total \\
\hline Ulnar styloid & 2 & 12 & 14 \\
Radiocarpal joint & 2 & 6 & 8 \\
Remainder of carpus & 2 & 9 & 11 \\
MCP & 1 & 14 & 15 \\
PIP & 2 & 10 & 12 \\
DIP & & 5 & 5 \\
MTP & 26 & 26 & 52 \\
IP Hallux & & 6 & 6 \\
\hline
\end{tabular}

MCP = metacarpophalangeal; $P I P, \quad D I P=$ proximal and distal interphalangeal; MTP = metatarsophalangeal.

\section{FREQUENCY OF JOINT INVOLVE MENT}

The total frequency of joint involvement over the follow-up period (mean 63.1 months) and the mean time to such involvement is shown in Table 3. While the earliest and most extensive erosive change

'Table 3 Cumulative frequency of erosive changes by joint groups ( $\%$ of 67 erosive cases)

\begin{tabular}{llllll}
\hline Joints & Mean $(m)$ & \multicolumn{5}{l}{ Cumulative \% at } \\
\cline { 3 - 6 } & & $12 m$ & $24 m$ & $36 m$ & Overall \\
\hline MTP & $10 \cdot 4$ & $70 \cdot 1$ & 89.6 & 97.0 & 100 \\
Carpal complex & $14 \cdot 2$ & 22.4 & $73 \cdot 1$ & 77.6 & 86.6 \\
MCP & $21 \cdot 3$ & $25 \cdot 4$ & $61 \cdot 2$ & $73 \cdot 1$ & 83.6 \\
PIP & 20.2 & 23.9 & $52 \cdot 2$ & 64.2 & 74.6 \\
\hline
\end{tabular}

was in the MTP joints, involvement of the carpug. metacarpophalangeal, and proximal interphalangeal joints became more common over the next 2 year $\overline{\overline{3}}$ Less commonly involved were the interphalanged joint of the hallux $(38.8 \%$ at 3 years with a mean 23.2 months) and the distal interphalangeal join $\overline{\bar{s}}$ of the hand $(14.9 \%$ at 3 years, mean 19.9 months).

\section{PROGRESSION OF EROSIVE DISEASE}

A progressive erosive disease was seen in $35(52.2 \%$ of the 67 patients to develop erosions. In the other $32(47.8 \%)$ patients the changes became stat after a mean 22.1 months, 25 of them within 2 year\& In many of the static cases the margins of the erosions became radiodense but normal appearances were never recovered.

\section{OSTEOPOROSIS}

Definite osteoporosis was seen on presentation in $26(27.6 \%)$ patients. A further 26 developed during follow-up, 18 of them during the next $\frac{9}{2}$ years. Of these $52(77.6 \%)$ patients, all but developed diagnostic erosions. Severe osteoporosis occurred in 8 patients; all had evidence of it at the first visit and the progression was rapid, within 3 years.

\section{JOINT-SPACE LOSS}

In only one patient did joint-space loss precede erosive change. In 4 cases it appeared at the time of 'nondiagnostic' erosive change, in $16(16.9 \%$ of the 67 erosive patients it occurred simultaneous with 'diagnostic' erosive change, and in $34(50.7 \%$ it followed 'diagnostic' change. Thus $55(82.1 \%)$ of 67 erosive patients eventually showed joint-space loss at a mean of 22.2 months. It appeared in the first year in 14 patients $(20.9 \%)$, in the second year in 19 , in the third year in 17, and after 3 years in $\Xi$.

\section{Discussion}

Recent years have seen the emergence of new drug treatments such as D-penicillamine and the cytotoxwe agents, and the re-evaluation of older treatments such as the gold salts. These drugs may alter the course of the disease, but have in common many potentially serious side effects. It is therefore imperay tive to identify those patients likely to have a poof prognosis and in this regard, the presence of an erosive arthropathy is crucial (Bywaters and Dresner, 1952; Fleming et al., 1975, 1976a). Furthe more, the identification of such patients is a matter of some urgency, for if these drugs are to modif the disease process they should be used before joing destruction becomes too advanced.

The literature gives little information as to the 
time of appearance of erosions. Our findings show clearly that it is a very early feature. In nearly $90 \%$ of patients erosions occurred within 2 years of onset of joint symptoms. For early diagnosis of an erosive of arthropathy, frequent $x$-rays of both feet and hands including the carpus are required in the first 2 years. We suggest that these be done every 4 to 6 months. The expected returns diminish markedly after the first 2 years.

We also found that osteoporosis was an early manifestation and could progress rapidly in the first 3 years. Very severe osteoporosis is not just a manifestation of long-standing rheumatoid disease. Jointspace loss, though not specific for rheumatoid disease, does indicate irreparable joint damage, and was an early feature in $49 \%$ of the erosive patients after 2 years, increasing in $75 \%$ after 3 years.

In nearly half our erosive patients the radiographic features became static. Surprisingly, this also occurred early. It will be of interest to follow these patients and compare their treatment and eventual clinical status with the remainder of the sample. We hope to report on this in due course.

We believe our patient sample is representative as the various $x$-ray manifestations in our material are in broad agreement with the overall frequency in larger earlier studies (Fletcher and Rowley, 1952; Soila, 1958; Berens and Lin, 1969).

We conclude from our findings that the most dramatic, rapid, and prognostically important radiographic changes in rheumatoid disease are part of the earliest features of the clincal course and that any consideration of the radiology in this disease must focus in detail on the first 2 years after onset.
We thank Drs O. Savage, A. C. Boyle, S. Mattingly, and $\mathrm{D}$. Woolf for allowing us to study their patients. Professor I. M. Roitt gave advice, and Harry L. Corbett did the calculations. The study has been generously supported by the Arthritis and Rheumatism Council.

\section{References}

Berens, D. L., and Lin, R.-K. (1969). Roentgen Diagnosis of Rheumatoid Arthritis. Thomas, Springfield, Ill.

Bywaters, E. G. L., and Dresner, E. (1952). The prognosis in rheumatoid arthritis. Quarterly Journal of Medicine, 21, 463.

Fleming, A., Crown, J. M., and Corbett, M. (1975). The relationship of early features to prognosis in rheumatoid disease. Scandinavian Journal of Rheumatology, Suppl. 8, 232.

Fleming, A., Crown, J. M., and Corbett, M. (1976a). Early rheumatoid disease. I. Onset. Annals of the Rheumatic Diseases, 35, 357-360.

Fleming, A., Dodman, S., Crown, J. M., and Corbett, M. (1976b). Extra-articular features in rheumatoid disease. British Medical Journal, 2, 1241-1243.

Fletcher, D. E., and Rowley, K. A. (1952). The radiological features of rheumatoid arthritis. British Journal of Radio$\log y, 25,282-295$.

Kellgren, J. H. (1956). Radiological signs of rheumatoid arthritis. A study of observer differences in the reading of hand films. Annals of the Rheumatic Diseases, 15, 55-60.

Nichols, E. H., and Richardson, F. L. (1909). Arthritis deformans. Journal of Medical Research, 21, 149-221.

Scott, S. G. (1932). The radiographic dissection of chronic rheumatoid arthritis. British Medical Journal, 1, 275-277.

Soila, P. (1958). Roentgen manifestations of adult rheumatoid arthritis. Acta Rheumatologica Scandinavica, Suppl. 1, 1-144. 